\title{
Fruit and vegetables intake among elderly Iranians: a theory-based interventional study using the five-a-day program
}

Leili Salehi $^{1,2}$, Kazem Mohammad ${ }^{3}$ and Ali Montazeri ${ }^{4^{*}}$

\begin{abstract}
Background: The benefit of FV intake in old age is well documented. However, there is evidence that old people do not consume enough FV. The purpose of this study was to evaluate the effectiveness of a tailored nutrition intervention that aimed to increase the FV intake among elderly Iranians aged 60 and over.

Methods: This quasi-experimental study was performed among a community-based sample of elderly in Tehran, Iran in year 2008 to 2009. Data were collected at baseline and 4 weeks follow-up. At baseline face-to-face interviews were conducted using a structured questionnaire including items on demographic information, stages of change, self-efficacy, decisional balance, daily servings of FV intake. Follow-up data were collected after implementing the intervention.
\end{abstract}

Results: In all 400 elderly were entered into the study (200 individuals in intervention group and 200 in control group). The mean age of participants was $64.06 \pm 4.48$ years and overall two-third of participants were female. At baseline total FV intake was not differed between two groups but it was significantly increased in the intervention group at posttest assessment (mean serving/day in intervention group $3.08 \pm 1.35$ vs. $1.79 \pm 1.08$ in control group; $P=0.001)$. Further analysis also indicated that elderly in intervention group had higher FV intake, perceived benefits and self-efficacy, and lower perceived barriers. Compared with control group, greater proportions of elderly in intervention group moved from pre-contemplation to contemplation/preparation and action/ maintenance stages $(P<0.0001)$, and from contemplation/preparation to action/maintenance stages $(P=0.004)$ from pretest to posttest assessments.

Conclusion: This study suggests that the Transtheoretical Model is a useful model that can be applied to dietary behavior change, more specifically FV consumption among elderly population in Iran and perhaps elsewhere with similar conditions.

\section{Background}

Adequate FV intakes could decrease risk of various chronic diseases such as cancers, cardiovascular disease, diabetes, and stroke [1-6]. The World Health Organization (WHO) dietary guideline recommends the minimum 5-a-day consumption of FV [7]. Individuals have not, as yet, adopted the minimum recommendations to consume five servings of FV per day in spite of all the benefits of FV on improving health and reducing the economic burdens of chronic disease. Based on data obtained from FV

\footnotetext{
* Correspondence: montazeri@acecr.ac.ir

${ }^{4}$ Mental Health Research Group, Mother and Child Health Research Centre, Iranian Institute for Health Sciences Research, ACECR, Tehran, Iran Full list of author information is available at the end of the article
}

intakes in 21 countries (mainly developing countries) only in three countries FV intake met the minimum WHO recommended consumption [8].

The benefit of FV intake in old age is well documented [9-11]. However, there is evidence that old people do not consume enough FV. For instance a study from Canada showed that only about $47 \%$ of elderly consume recommend amount of FV [12]. Data from a study of 400 elderly in Iran showed that FV consumption among participations was low. Overall the mean serving of FV consumption eaten per day for the elderly was 1.76 (SD = 1.15) [13]. Another cross sectional study showed that the prevalence of daily FV intake of 5 or more serving was

\section{Biomed Central}


$37 \%$ and the mean daily FV consumption separately was $1.86 \pm 0.68$ and $2.74 \pm 0.83$ respectively [14].

Such observations from Iran and elsewhere indicate that there is urgent need for health promotion programs in order to increase FV consumption among elderly population. But, the debate about effectiveness of these programs still remains [15]. It is argued that these programs, at least, should be theory driven if one expects any appropriate changes in dietary behaviors [16]. The Transtheoretical Model (TTM) of behavior change is one of the most popular models for studying behavioral change in health education/promotion programs. This model assumes that health behavior change involves progress through six stages: pre-contemplation (unaware of a problem and/or not intending to change), contemplation (considering a change and thinking about it), preparation (intending to take action in very near future), action (initiating a new behavior), maintenance (in which people strive to prevent relapse), and termination (in which individuals show complete self-efficacy) [17].

Several studies showed that dietary interventions based on stages of change model are effective in increasing FV intake [18-20]. Only a few studies however have been conducted using the TTM for elderly population $[21,22]$. The purpose of this study was to evaluate the effectiveness of a tailored nutrition intervention that aimed to increase the FV intake among elderly Iranians. According to the report by Iranian Ministry of Health the proportion of elderly $(\geq 65)$ in Iran accounts for 5.4 percent and it is estimated that this rate will be rise to 10.5 percent by 2025 [23]. To our best knowledge this is the first paper from Iran that reports on the topic.

\section{Methods}

\section{Design and data collection}

This quasi-experimental study was performed among a community-based sample of elderly people aged 60 and over in Tehran, Iran in year 2008 to 2009. Data were collected at baseline and 4 weeks follow-up. At baseline faceto-face interviews were conducted with the whole sample using a structured questionnaire including items on demographic information, stages of change, self-efficacy, decisional balance, daily servings of FV intake. Four weeks follow-up data were collected after implementing the intervention.

\section{Participants}

Of 30 existing elderly centers in Tehran, 10 centers were randomly selected through multistage sampling to represent centers from all 5 main areas in Tehran (2 centers from each area: south, north, east, west and city center). Within the 10 selected centers the membership list for each center was asked and relative to density a systematic sampling method was applied. The selected participants contacted and asked if they were willing to participate in the study. Participants were also informed about the study and the number of required meetings during the study. Participants were then randomized to the intervention or the control groups. A health professional not connected to the study carried out the randomization. People in both groups received a four-cession program.

\section{Measures}

Several instruments were used to collect data:

\section{Demographic and anthropometrics Questionnaire}

This comprised three sections covering demographic and anthropometrics data including information on age, sex, education, income, marital status, health status (having chronic disease or not) and body mass index (BMI). Chronic disease was indicated by asking each individual to respond to the following question: 'Do you have any longstanding disease?' Anyone who responded positively then was asked to name the disease. Weight was measured using the same digital scales [SECA, Calibrated in Iran] while the participants were minimally clothed and not wearing shoes. Height was measured by a tape measure while the respondents were standing and not wearing shoes and the shoulders were in a normal position. BMI was calculated and expressed in $\mathrm{kg} / \mathrm{m}^{2}$, and economic status was measured using the asset-based approach developed by Ferguson and colleagues [24] and used in previous cross-national studies of economic status and health in developing countries [25]. According to this scale, 0-3 assets were considered low, 4-6 assets were considered intermediate and 8 or more assets were considered high economic status. The items considered as assets were: television, refrigerator, washing mashing, microwave oven, dish-washer, computer, electrical sweeper, automobile and phone.

\section{Stages of change questionnaire regarding FV consumption behavior}

This part of questionnaire adapted from the literature [26] and was consisted of five statements by which the participants were categorized into different stages of change: pre-contemplation, contemplation, preparation, action and maintenance. In fact the participants were asked to respond to one question choosing the statement that best described their status. Choices for the response were: (1) I am not currently consuming five servings of FV a day and I am not thinking of doing so in the upcoming six months, (2) I am not currently consuming five servings of FV a day but I plan to do so within the next six months. (3) I am not currently consuming five servings of FV a day but I plan to do so within the next month (4) I am currently consuming five servings of FV a day but I have been doing so for less than six months (5) I am currently consuming five servings of FV a day but I have been doing that for more than six months. 


\section{Self-efficacy}

Self-efficacy was assessed to measure confidence in one's ability to persist with FV consumption in various situations. It was assessed using a five item questionnaire developed by Ma et al. [26] and participants were asked to respond to these items: 'I can keep fruits and vegetables at hand/readily available'; 'When I have the chance to choose, I can eat the recommended number of servings of fruits and vegetables'; 'I can shop for a variety of fruits and vegetables'; 'I can make time to eat fruits and vegetables'; 'When I eat at home, I can eat more fruits and vegetables'. Each item is rated on a 5-point scale (from not at all confident $=0$ to very confident about recommended $\mathrm{FV}$ consumption $=5$ ). The total score ranged from 5 to 25 with higher scores indicating a greater degree of self-efficacy.

\section{Perceived benefits and barriers regarding FV consumption}

This part was generated from previous studies and focus group discussions with convenient sample of elderly individuals. Participants were asked about their perception regarding amount of FV intake. The perceived benefit consisted of 15 items and each item is rated on a 5-point scale ranging from 'strongly agree' to 'strongly disagree'. The perceived barrier consisted of 11 items and each item is also rated on a 5-point scale ranging from 'strongly agree' to 'strongly disagree'. The total score for the perceived benefits ranged from 15 to 75 and for perceived barriers from 11 to 55 (Table 1).

\section{Daily FV consumption}

The section comprised two parts as follows.

Table 1 Perceived benefits and barriers questionnaire

\begin{tabular}{|c|c|c|c|c|c|}
\hline & $\begin{array}{l}\text { Strongly } \\
\text { agree }\end{array}$ & Agree & $\begin{array}{l}\text { Neither agree nor } \\
\text { disagree }\end{array}$ & Disagree & $\begin{array}{l}\text { Strongly } \\
\text { disagree }\end{array}$ \\
\hline \multicolumn{6}{|l|}{ Perceived Benefits } \\
\hline \multicolumn{6}{|l|}{ I could find any types of FV in my local stores } \\
\hline \multicolumn{6}{|l|}{$\begin{array}{l}\text { It is better to get all nutrients from FV than taking } \\
\text { supplements }\end{array}$} \\
\hline \multicolumn{6}{|l|}{ FV decrease the risk of chronic diseases } \\
\hline \multicolumn{6}{|l|}{ FV make our diet diverse } \\
\hline \multicolumn{6}{|l|}{ Eating FV is a good way for treating chronic diseases } \\
\hline \multicolumn{6}{|l|}{ Eating FV would help me to be less aggressive } \\
\hline \multicolumn{6}{|l|}{ Eating FV treats constipation } \\
\hline \multicolumn{6}{|l|}{ Eating FV would help me to maintain my weight } \\
\hline \multicolumn{6}{|l|}{ FV consumption are recommended by physicians } \\
\hline \multicolumn{6}{|l|}{ Eating FV cheering my family members } \\
\hline \multicolumn{6}{|l|}{ Eating FV is common in my culture } \\
\hline \multicolumn{6}{|l|}{ Eating FV would keep me of sickness } \\
\hline \multicolumn{6}{|l|}{ Eating FV would help me to live longer } \\
\hline \multicolumn{6}{|l|}{ I feel that if I eat more FV, I will be more healthy } \\
\hline \multicolumn{6}{|l|}{ By eating $F V$, I feel better } \\
\hline \multicolumn{6}{|l|}{ Perceived Barriers } \\
\hline \multicolumn{6}{|l|}{ Providing FV is expensive } \\
\hline \multicolumn{6}{|l|}{ I did not used to eat FV since childhood } \\
\hline \multicolumn{6}{|l|}{ Eating FV leads to overeating } \\
\hline \multicolumn{6}{|l|}{ Media advertisements are not about eating FV } \\
\hline \multicolumn{6}{|l|}{ Eating more FV is not recommended in my culture } \\
\hline \multicolumn{6}{|l|}{ My family members do not like consumption of FV } \\
\hline \multicolumn{6}{|l|}{ Eating more FV is difficult for me } \\
\hline \multicolumn{6}{|l|}{ I have health problems with eating FV (e.g. flatus) } \\
\hline \multicolumn{6}{|l|}{ I have limitations to provide FV in my meal } \\
\hline \multicolumn{6}{|l|}{ I do not like taste of FV } \\
\hline I do not have time to provide FV & & & & & \\
\hline
\end{tabular}


5.1. Food frequency questionnaire This was consisted of two main questions related to fruits and vegetables (38 items in all) available in Tehran's markets. Response categories were: never, 1-2 times per week, 3-4 times per week, 5-6 times per week, and every day. Accordingly the respondents were asked to indicate the amount of intake.

5.2. A 24 hour recall participants were asked to estimate their daily servings of FV at breakfast, lunch, dinner, and between meals as snacks or deserts in accordance with a nutrition guideline cards. The nutrition guideline card categorized one serving of vegetables into one of three following groups: (1) one cup of raw green leafy vegetables such as spinach or salad; (2) one-half cup of other vegetables cooked or chopped raw, such as tomatoes, carrots, pumpkin, corn, Chinese Cabbage, beans, or onions; and (3) one half cup of vegetable juice. The nutrition guideline categorized one serving of fruit into one of three groups: (1) one medium size fruit such as an apple, banana, or orange; (2) one half cup of cooked, chopped, or canned fruit; and (3) one-half cup of fruit cup of fruit juice, not artificially flavored.

We calculated the daily serving FV consumption for each individual according to information provided from the above-mentioned measures. This included of calculation of weekly consumption of FV based on frequency and portion of each item in the food frequency questionnaire. Then we compared total score of daily FV consumption between two groups.

\section{Intervention}

Both those randomized to the control group and those randomized to the intervention group received four weekly sessions. The control group sessions focused on general health education and did not include content related to the health benefits of fruits and vegetables, while the intervention group sessions were focused on increasing fruit and vegetable intake.

After randomization, those randomized to intervention group were further divided by stages of change and the sessions were then tailored to that stages of change and techniques (processes) associated with the stages of change. The goal of the intervention was to increase participants' consumption of FV to 5 servings per day. The intervention was composed of four consecutive sessions (one meeting per week). Each session was around 90 minutes in length and included a 40-minute power point presentation, 30 minutes discussion, 10 minutes questions and answers, and 10 minutes reception with FV.

(I) The first session was introductory.

(II) During the second session, the stages of change for FV intake was assessed in participants in order to deliver the appropriate intervention. Based on each individual's status at least one tailored technique (according to the Transtheoretical Model) was used:
(II-a) Participants in pre-contemplation stage completed session that incorporated conscious raising (raising awareness about unhealthy dietary behavior); dramatic relief (react emotionally to warnings about unhealthy dietary behavior. The topics included personal recommendation regarding losing a loved one due to a chronic disease and discussion of nutritional habits associated with this chronic disease; emotional arousal (which is a certain technique that produce increased emotional experiences that can encourage people towards an action. In fact, this process of behavioral change was used to help the participants understand the relationship between lower consumption of FV and increased risk for chronic diseases. The topics included the statistics about the prevalence of the previously mentioned chronic diseases in world and in Iran, the scientific studies relating the protective effect of FV against each of these diseases); and environmental reevaluation (assessing the impact of one's dietary behavior on family members and others).

(II-b) Participants in contemplation/preparation stage completed session that incorporated self-evaluation (which is an assessment of one's self-image with and without a particular unhealthy habit. The researcher asked the participants who were now consuming 5 servings of FV per day to compare their lifestyle and diet before and after increasing their intake of FV to five or more servings per day); and self-liberation (which is the belief that one can change and have the commitment to act on that belief. Participants were asked to make a plan and set a goal and be committed to that goal).

(II-c) Participants in the action/maintenance stage completed session that incorporated helping relationship (which is defined as having a caring, trusted, and accepted person who can give the support and the counseling for the healthy behavior change), stimulus control (removing or countering stimuli that elicit problem behavior), reinforcement management (rewarding oneself or being rewarded by others for making dietary change).

(III) During the third session, the content of the second session was reinforced.

(IV) The fourth session was planned to help participants anticipate and overcome barriers, increase selfassurance and self-efficacy in addition to improve skills in obtaining and arranging FV.

\section{Statistical Analysis}

The characteristics of participants in two groups were compared using analysis of variance and $\mathrm{x}^{2}$ tests as appropriate. Responses to the interventions were assessed by calculating changes in fruit and vegetable intake from baseline to 4 weeks, with positive values indicating an increase in consumption at follow-up assessment. Similar analysis was performed for assessment of stages of change 
(posttest data vs. pre-contemplation, contemplation/preparation, and action/maintenance at baseline). The data were analyzed on an intention to treat basis including all 400 participants. Analysis of covariance (ANCOVA) was used, controlling for variables previously shown to be related to FV consumption, namely, age, education, marital status, income, chronic disease and BMI. All analyses were conducted using SPSS 16.0. Alpha level of .05 was used for all statistical tests.

\section{Outcome measures}

Two main outcomes of the current study were changes in FV intake and to examine the stage transitions.

\section{Ethics}

Ethics committee of Tehran University of Medical Sciences approved the study. All participants singed a consent form.

\section{Results}

The study samples

In all 400 elderly were entered into the study (200 individuals in intervention group and 200 in control group). The two groups did not differ in terms of demographic characteristics. The mean age of participants was 64.06 $(\mathrm{SD}=4.48)$ years and overall two-third of participants were female $(n=298,74.5 \%)$. The characteristics of participants in the two groups are shown in Table 2.

\section{Change in FV intake}

At baseline total FV intake was not differed between two groups (intervention and control groups) but it was significantly increased in the intervention group at posttest assessment (mean serving/day in intervention group $3.08 \pm 1.35$ vs. $1.79 \pm 1.08$ in control group; $\mathrm{P}=$ 0.001). The detailed results are shown in Table 3 and Table 4. Pearson correlation also showed significant

Table 2 The characteristics of the study sample

\begin{tabular}{|c|c|c|c|c|}
\hline & Total & Intervention group $(n=200)$ & Control group $(n=200)$ & \\
\hline & No. (\%) & No. (\%) & No. (\%) & $\mathbf{P}$ \\
\hline Age & & & & 0.55 \\
\hline $60-64$ & $255(63.8)$ & $120(65.0)$ & $125(62.5)$ & \\
\hline $65-69$ & $87(21.7)$ & $34(17.0)$ & $53(26.5)$ & \\
\hline 70-74 & $47(11.7)$ & $30(15.0)$ & $17(8.5)$ & \\
\hline$\geq 75$ & $11(2.8)$ & $6(3.0)$ & $5(2.5)$ & \\
\hline Mean (SD) & $64.06(4.48)$ & $63.93(5.08)$ & $64.2(3.8)$ & \\
\hline \multicolumn{5}{|l|}{ Gender } \\
\hline Female & $298(74.5)$ & $144(72.0)$ & $154(77.0)$ & 0.81 \\
\hline Male & $102(25.5)$ & $56(28.0)$ & $46(23.0)$ & \\
\hline Education & & & & 0.08 \\
\hline Illiterate & $165(41.2)$ & $82(41.0)$ & $83(41.5)$ & \\
\hline Primary & $143(35.8)$ & $82(41.0)$ & $61(30.5)$ & \\
\hline Junior Secondary & $64(17.0)$ & $23(11.5)$ & $41(20.5)$ & \\
\hline Senior Secondary \& above & $28(7.0)$ & $13(6.5)$ & $15(7.5)$ & \\
\hline \multicolumn{5}{|l|}{ Marital status } \\
\hline Married & $230(55.0)$ & $120(60.0)$ & $110(55.0)$ & 0.45 \\
\hline Never married/Divorced/widow & $170(45.0)$ & $80(40.0)$ & $90(45.0)$ & \\
\hline Income & & & & 0.03 \\
\hline Low (0-3assets) & $306(76.5)$ & $165(82.5)$ & $141(70.5)$ & \\
\hline Moderate (4-6 asset) & $65(16.2)$ & $22(11.0)$ & $43(21.5)$ & \\
\hline High (8 or more assets) & $29(7.3)$ & $13(6.5)$ & $16(8.0)$ & \\
\hline Employment status & & & & 0.45 \\
\hline Employed & $54(13.5)$ & $31(15.5)$ & $23(21.5)$ & \\
\hline Housewife & $283(70.8)$ & $133(66.5)$ & $150(70.0)$ & \\
\hline Retired & $63(15.7)$ & $36(18.0)$ & $27(13.5)$ & \\
\hline BMI & & & & 0.79 \\
\hline$<25$ & $106(26.5)$ & $56(28.0)$ & $50(25.0)$ & \\
\hline $25-29$ & $192(48)$ & $94(47.0)$ & $98(49.0)$ & \\
\hline$\geq 30$ & $103(25.5)$ & $50(25.0)$ & $52(26.0)$ & \\
\hline
\end{tabular}


Table 3 Comparison of perceived benefits, perceived barriers, self-efficacy and FV consumption between two groups

\begin{tabular}{lllllll}
\hline & Before & & & After & \\
\hline & Intervention group & Control group & & Intervention group & Control group \\
\hline & Mean (SD) & Mean (SD) & $\mathbf{P}$ & Mean (SD) & Mean (SD) & P \\
\hline Perceived Benefits & $54.91(9.29)$ & $56.62(8.34)$ & 0.21 & $64.34(9.11)$ & $57.01(8.47)$ & $<0.001$ \\
\hline Perceived Barriers & $34.23(8.04)$ & $35.79(8.29)$ & 0.50 & $27.32(8.09)$ & $35.89(8.72)$ & $<0.001$ \\
\hline Self-efficacy & $13.59(6.41)$ & $12.72(6.02)$ & 0.22 & $19.23(5.72)$ & $12.79(6.04)$ & $<0.001$ \\
\hline FV Consumption & $1.78(1.21)$ & $1.75(1.09)$ & 0.17 & $3.08(1.36)$ & $1.79(1.08)$ & $<0.001$ \\
\hline
\end{tabular}

correlation between stages of change and benefits, barriers, self-efficacy and FV intake (Table 5). Further analysis of the data performing the analysis of variance adjusting for covariate also indicated that there were significant differences between intervention and control groups Elderly in intervention group had higher FV intake, perceived benefits and self-efficacy, and lower perceived barriers. The results are presented in (Table 6).

\section{Change in stage transition}

There was no difference at baseline in distribution of the stages of change between the two groups. Larger number of participants fell into the pre-contemplation stage than the other stages. Compared with control group, greater proportions of elderly in intervention group moved from pre-contemplation to contemplation/preparation and action/maintenance stages $\left(\chi^{2}=233.7, \mathrm{P}<0.0001\right)$, and from contemplation/preparation to action/maintenance stages $\left(\chi^{2}=8.1, \mathrm{P}=0.004\right)$ from pretest to posttest measurements (Table 7).

\section{Discussion}

This study indicated the efficacy of a TTM-based intervention for increasing fruit and vegetable consumption in elderly. The findings also confirmed that a theory driven program could have effect on stages of change in elderly in order to improve their lifestyle and health behavior.

We found an average increase of 1.29 daily servings of fruits and vegetables in the intervention group. The results from current study were very similar to those reported by other investigators. For instance, an interventional study that applied the TTM to promote FV consumption showed that FV intake in elderly increased from 0.5 to 1.0 serving a day [22]. Another study reported a significant increase in FV consumption; 1.49 serving/day increase when using a theory based intervention [27]. Di Noia et al. conducted the TTM based study with urban African-American adolescents to determine whether the delivery of stage-tailored change process would promote movement through successive stages and effect positive changes in FV consumption, pros, cons and self efficacy and found that the intervention group had greater increase in the perceived pros of eating FV and increase of 0.9 daily serving of FV compared with the control group [28]. Similarly our findings demonstrated that the intervention had positive effect on perceived benefits and barriers, and self-efficacy. We believe the strength of the current study was due to the fact that our intervention not only was drawn from the TTM stages of change, but also it included examination of perceived barriers and self-efficacy.

Overall most interventional studies based on the TTM model showed that the interventions have produced positive influence on FV intakes. However, the program developed by Amanda Park indicated that stage-tailored nutrition education produced positive shift in several indicators and mediators of vegetables but not for fruits intake [29]. Our study assessed both fruits and vegetables together. Hence it is better to assess the two items apart in future studies as a match-mismatch test. A study was conducted to test the transtheoretical model applied to fruit intake and failed to support the superiority of stage-matching compared with stagemismatching [30].

Table 4 Comparison of perceived benefits, perceived barriers, self-efficacy and FV consumption within groups

\begin{tabular}{|c|c|c|c|c|c|c|}
\hline & \multicolumn{3}{|c|}{ Intervention group } & \multicolumn{3}{|c|}{ Control group } \\
\hline & Before & After & & Before & After & \\
\hline & Mean (SD) & Mean (SD) & $\mathbf{P}$ & Mean (SD) & Mean (SD) & $\mathbf{P}$ \\
\hline Perceived Benefits & $54.91(9.29)$ & $64.35(9.11)$ & $<0.001$ & $56.62(8.34)$ & $57.01(8.47)$ & $<0.001$ \\
\hline Perceived Barriers & $34.23(8.04)$ & $27.33(8.09)$ & $<0.001$ & $35.79(8.29)$ & $35.89(8.72)$ & 0.262 \\
\hline Self-efficacy & $13.59(6.41)$ & $19.23(5.72)$ & $<0.001$ & $12.72(6.02)$ & $12.79(6.04)$ & 0.007 \\
\hline FV Consumption & $1.78(1.21)$ & $3.08(1.36)$ & $<0.001$ & $1.75(1.09)$ & $1.79(1.08)$ & 0.006 \\
\hline
\end{tabular}


Table 5 Correlation between stage of change, benefits, barriers, self-efficacy and FV consumption*

\begin{tabular}{llllll}
\hline & Stages of change & Benefits & Barriers & Self-efficacy & FV consumption \\
\hline Stages of change & 1 & $0.213^{* *}$ & $-0.181^{* *}$ & $0.181^{* *}$ & $0.448^{* *}$ \\
\hline Benefits & $0.371^{* *}$ & 1 & -0.033 & 0.096 & $0.237^{* *}$ \\
\hline Barriers & $-0.403^{* *}$ & $-0.217^{* *}$ & 1 & $-0.173^{* *}$ & $-0.296^{* *}$ \\
\hline Self-efficacy & $0.437^{* *}$ & $0.303^{* *}$ & $-0.375^{* *}$ & 1 & $0.337^{* *}$ \\
\hline FV consumption & $0.636^{* *}$ & $0.355^{* *}$ & $-0.402^{* *}$ & $-0.485^{* *}$ & 1 \\
\hline
\end{tabular}

* Figures above triangle relate to before intervention and figures below triangle relate to after intervention

** Correlation is significant at the 0.01 levels.

Table 6 Analysis of covariance of perceived benefit, perceived barrier, self-efficacy, and FV consumption

\begin{tabular}{|c|c|c|c|c|c|}
\hline Source of variance & Type III sum of square & df. & Mean square & F statistic & $\mathbf{P}$ \\
\hline \multicolumn{6}{|l|}{ Perceived Benefit } \\
\hline Arm & 6846.086 & 1 & 6846.086 & 179.074 & $<0.0001$ \\
\hline Pretest & 15388.664 & 1 & 15388.664 & 402.523 & $<0.0001$ \\
\hline Age & 14.127 & 1 & 14.127 & 0.37 & 0.544 \\
\hline Education & 11.286 & 1 & 11.286 & 0.295 & 0.587 \\
\hline Marital status & 77.527 & 1 & 77.527 & 2.028 & 0.155 \\
\hline Income & 65.055 & 1 & 65.055 & 1.702 & 0.193 \\
\hline Chronic disease & 50.452 & 1 & 50.452 & 1.32 & 0.251 \\
\hline$\overline{\mathrm{BMI}}$ & 41.750 & 1 & 41.750 & 1.092 & 0.297 \\
\hline Error & 14948.144 & 391 & 38.231 & & \\
\hline \multicolumn{6}{|l|}{ Perceived Barrier } \\
\hline Arm & 5423.038 & 1 & 5423.038 & 174.115 & $<0.0001$ \\
\hline Pretest & 13877.096 & 1 & 13877.096 & 455.545 & $<0.0001$ \\
\hline$\overline{\text { Age }}$ & 38.961 & 1 & 38.961 & 1.251 & 0.264 \\
\hline Education & 80.167 & 1 & 80.167 & 2.574 & 0.109 \\
\hline Marital status & 19.014 & 1 & 19.014 & 0.61 & 0.435 \\
\hline Income & 50.268 & 1 & 50.268 & 1.614 & 0.205 \\
\hline Chronic disease & 2.029 & 1 & 2.029 & 0.065 & 0.799 \\
\hline$\overline{\mathrm{BMI}}$ & 0.172 & 1 & 0.172 & 0.006 & 0.941 \\
\hline Error & 12178.223 & 391 & 31.146 & & \\
\hline \multicolumn{6}{|l|}{ Self-efficacy } \\
\hline Arm & 3252.374 & 1 & 3252.374 & 475.144 & $<0.0001$ \\
\hline Pretest & 9563.134 & 1 & 9563.134 & 1.397 & $<0.0001$ \\
\hline Age & 23.900 & 1 & 23.900 & 3.492 & 0.062 \\
\hline Education & 5.188 & 1 & 5.188 & 0.758 & 0.385 \\
\hline Marital status & 1.006 & 1 & 1.006 & 0.147 & 0.703 \\
\hline Income & 30.368 & 1 & 30.368 & 4.436 & 0.036 \\
\hline Chronic disease & 1.022 & 1 & 1.022 & 0.149 & 0.699 \\
\hline$\overline{\mathrm{BMI}}$ & 0.282 & 1 & 0.282 & 0.041 & 0.839 \\
\hline Error & 2676.407 & 391 & 6.845 & & \\
\hline \multicolumn{6}{|l|}{ FV consumption } \\
\hline$\overline{A r m}$ & 156.226 & 1 & 156.226 & 294.929 & $<0.0001$ \\
\hline Pretest & 218.617 & 1 & 218.617 & 412.712 & $<0.0001$ \\
\hline$\overline{\text { Age }}$ & 2.400 & 1 & 2.400 & 4.530 & 0.034 \\
\hline Education & 0.017 & 1 & 0.017 & 0.032 & 0.858 \\
\hline Marital status & 1.301 & 1 & 1.301 & 2.456 & 0.118 \\
\hline
\end{tabular}


Table 6 Analysis of covariance of perceived benefit, perceived barrier, self-efficacy, and FV consumption (Continued)

\begin{tabular}{llllll}
\hline Income & 0.055 & 1 & 0.055 & 0.105 & 0.746 \\
\hline Chronic disease & 0.198 & 1 & 0.198 & 0.374 & 0.541 \\
\hline BMI & 0.062 & 1 & 0.062 & 0.118 & 0.732 \\
\hline Error & 207.116 & 391 & 0.530 & & \\
\hline
\end{tabular}

Table 7 Chi-square analysis of between groups differences in posttest stages of change by pretest stages of change*

\begin{tabular}{|c|c|c|c|c|c|}
\hline & \multicolumn{5}{|c|}{ Post test stages of change } \\
\hline & $P C$ & $C / P R$ & $A / M$ & $\chi^{2}(d f)$ & $P$ \\
\hline \multicolumn{6}{|c|}{ Pretest stages of change } \\
\hline \multicolumn{6}{|l|}{$\overline{P C}$} \\
\hline Intervention $(n=140)$ & 5 & 117 & 18 & & \\
\hline \multirow[t]{2}{*}{ Control $(n=143)$} & 135 & 8 & 0 & & \\
\hline & & & & $233.7(2)$ & $<0.0001$ \\
\hline \multicolumn{6}{|l|}{$C / P R$} \\
\hline Intervention $(n=53)$ & 0 & 45 & 8 & & \\
\hline \multirow[t]{2}{*}{ Control $(n=50)$} & 0 & 50 & 0 & & \\
\hline & & & & $8.1(1)$ & 0.004 \\
\hline \multicolumn{6}{|l|}{$A / M^{* *}$} \\
\hline Intervention $(n=7)$ & 0 & 0 & 7 & & \\
\hline Control $(n=7)$ & 0 & 0 & 7 & & \\
\hline
\end{tabular}

\section{Limitations}

Given that all our respondents were members of elderly centers, the findings of this study might not be generalized to all elderly Tehran residents. These elderly might differ from others in Tehran in terms of socioeconomic status, family cohesiveness, social support and availability and access to FV. In addition, it should be noted that our findings on FV intake were based on self-reported information and it might be associated with measurement errors.

\section{Conclusion}

This study demonstrated that the TTM is a useful model that can be applied to dietary behavior change, more specifically FV consumption among elderly populations.

\footnotetext{
Author details

'Tehran University of Medical Sciences, Center for Community Based Participatory Research (CBPR), Tehran, Iran. ${ }^{2}$ Alborz University of Medical Sciences, Karaj, Iran. ${ }^{3}$ Department of Epidemiology and Statistics, School of Public Health, Tehran University of Medical Sciences, Tehran, Iran. ${ }^{4}$ Mental Health Research Group, Mother and Child Health Research Centre, Iranian Institute for Health Sciences Research, ACECR, Tehran, Iran.
}

\section{Authors' contributions}

LS was the main investigator, analyzed the data and involved in drafting the manuscript. KM contributed to the study design and statistical analysis, and supervised the study. AM contributed to statistical analysis, edited the paper and provided the final version. All authors read and approved the final manuscript.

\section{Competing interests}

The authors declare that they have no competing interests.

Received: 4 January 2011 Accepted: 14 November 2011

Published: 14 November 2011

\section{References}

1. Dosil-Díaz O, Ruano-Ravina A, Gestal-Otero JJ, Barros-Dios JM: Consumption of fruit and vegetable and risk of lung cancer: a case-control study in Galicia, Spain. Nutrition 2008, 24:407-413.

2. Dauchet $L$, Dallongeville J: Fruit and vegetables and cardiovascular disease: epidemiological evidence from the non western world. Br J Nutr 2008, 99:398-405.

3. Harding AH, Wareham NJ, Bingham SA, Khaw K, Luben R, Welch A, Forouhi NG: Plasma vitamin C level, fruit and vegetable consumption, and the risk of new-onset type 2 diabetes mellitus: the European prospective investigation of cancer-Norfolk prospective study. Arch Intern Med 2008, 168:1493-1499.

4. He FJ, Nowson CA, Macaregor CA: Fruit and vegetable consumption and stroke: meta-analysis of cohort studies. Lancet 2006, 367:320-326.

5. Ebrahimi SF, Hoshyarra A, Hossein-Nezhad A, Zandi N, Larijani B, Kimiagar M: Fruit and vegetable intake in postmenopausal women with osteopenia. Arya Atherosclerosis 2006, 1:183-187.

6. DiBello JR, Kraft P, McGarvey ST, Goldberg R, Campos H, Baylin A: Comparison of 3 methods for identifying dietary patterns associated with risk of disease. Am J Epidemiol 2008, 168:1433-1443.

7. World Health Organization: Diet, nutrition and the prevention of chronic diseases. Report of a Joint WHO/FAO Expert consultation Geneva: World Health Organization; 2003.

8. International Agency for Research on Cancer (IARC): Handbook of Cancer Prevention Lyon: IARC Press; 2003.

9. Dauchet L, Amouyel P, Dallongeville J: Fruit and vegetable consumption and risk of stroke: a meta-analysis of cohort studies. Neurology 2005, 65:1193-1197.

10. Moaffarian D, Kumanyika SK, Lemitre RN, Olson JL, Burke GL, Siscovick DS: Cereal, fruit and vegetable fiber intake and the risk of cardiovascular disease in elderly individuals. JAMA 2003, 289:1659-1666.

11. Ritchie K, Carrière I, Ritchie CW, Berr C, Artero S, Ancelin ML: Designing prevention programmes to reduce incidence of dementia: prospective cohort study of modifiable risk factors. BMJ 2010, 341:c3885.

12. Riedger ND, Moghadasian MH: Patterns of fruit and vegetable consumption and influence of sex, age and sociodemographic factors among Canadian elderly. Am Coll Nutr 2008, 27:306-313.

13. Salehi L, Efthekhar H, Mohammad K, Tavafian SS, Jazayery A, Montazeri A: Consumption of fruit and vegetables among elderly people: a cross sectional study from Iran. Nutrition Journal 2010, 1:2.

14. Sabzghabaee AM, Mirmoghtadaee P, Mohammadi M: Fruit and vegetable consumption among community dwelling elderly in an Iranian population. Int J Prev Med 2010, 1:99-103.

15. Noar SM, Benac C, Harris M: Does tailoring matter? Meta analytic review of tailored print health behavior change interventions. Psychol Bull 2007, 133:673-693.

16. Brug J, Oenema A, Ferreira I: Theory, evidence and intervention mapping to improve behavior nutrition and physical activity interventions. Int J Behav Nutr Phys Act 2005, 2:2 
17. Prochaska JO, Reddind CA, Ever KE: The Transtheoretical Model and stage of change. In Health Behavior and Health Education, Theory, Research and Practice. Edited by: Glanz K, Rimer BK, Lewis FM. San Francisco: Jossey-Bass; 2008:97-121.

18. Alexander GL, McClure JB, Calvi JH, Divine GW, Stopponi MA, Rolnick SJ, Heimendinger J, Tolsma DD, Resnicow K, Campbell MK, Strecher VJ, Johnson CC: A randomized clinical trial evaluating online interventions to improve fruit and vegetable consumption. Am J Public Health 2010, 100:319-326.

19. Horwath CC, Nigg CR, Motl RW, Wong KT, Dishman RK: Investigating fruit and vegetable consumption using the transtheoretical model. Am J Health Promot 2010, 24:324-333.

20. Di Noia J, Prochaska JO: Dietary stages of change and decisional balance: a meta-analytic review. Am J Health Behav 2010, 34:618-632.

21. Bradbury J, Thomason JM, Jepson NJ, Walls AW, Allen PF, Moynihan PJ: Nutrition counseling increases fruit and vegetable intake in the edentulous. J Dent Res 2006, 85:463-468.

22. Greene GW, Fey-Yensan N, Padula C, Rossi SR, Rossi JS, Clark PG: Change in fruit and vegetable intake over 24 months in older adults: results of the SENIOR project intervention. Gerontologist 2008, 48:378-387.

23. United Nations: World Population Ageing: 1950-2050, Countries of area: Iran (Islamic Republic of), http://www.un.org/esa/population/publications/ worldageing19502050/pdf/113iran..pdf[accessed 05.05.2008].

24. Ferguson BD, Tandon A, Gakidou E, Murray CJL: Estimating permanent income using indicator variable. In Health System Performance Assessment: Debates, Methods and Empiricism. Edited by: Murray CJL, Evans DB. Geneva: WHO; 2003:747-760.

25. Chatterji S, Kowal P, Mathers C, Naidoo N, Verdes E, Smith JP, Suman R: The health of ageing population in China and India. Health Affairs 2008, 27:1052-1063.

26. Ma J, Betts NM, Horacek T, Georgiou C, White A, Nitzke S: The importance of decisional balance and self-efficacy in relation to stages of change for fruit and vegetable intakes by young adults. Am J Health Promot 2002, 16:157-166.

27. Steptoe A, Perkins-Porras L, McKay C, Rink E, Hilton S, Cappuccio FP: Behavioral counseling to increase consumption of fruit and vegetables in low income adults: randomized trial. BMJ 2003, 326:855.

28. Di Noia J, Contento IR, Prochaska JO: Computer-mediated intervention tailored on transtheoretical model stages and processes of change increases fruit and vegetable consumption among urban AfricanAmerican adolescents. Am J Health Promot 2008, 22:336-341.

29. Park A, Nitzke S, Kritsch K, Kattelmann K, White A, Boeckner L, Lohse B, Hoerr S, Greene G, Zhang Z: Internet-based interventions have potential to affect short-term mediators and indicators of dietary behavior of young adults. J Nutr Educ Behav 2008, 40:288-297.

30. de Vet E, de Nooijer J, de Vries NK, Brug J: Testing the transtheoretical model for fruit intake: comparing web-based tailored stage-matched and stage-mismatched feedback. Health Educ Res 2008, 23:218-227.

doi:10.1186/1475-2891-10-123

Cite this article as: Salehi et al.: Fruit and vegetables intake among elderly Iranians: a theory-based interventional study using the five-aday program. Nutrition Journal 2011 10:123.

\section{Submit your next manuscript to BioMed Central and take full advantage of:}

- Convenient online submission

- Thorough peer review

- No space constraints or color figure charges

- Immediate publication on acceptance

- Inclusion in PubMed, CAS, Scopus and Google Scholar

- Research which is freely available for redistribution

Submit your manuscript at www.biomedcentral.com/submit
Biomed Central 